\title{
Causes of Sudden Natural Death in Adults: A Retrospective Study from Malatya Province, Turkey
}

\author{
Fatma Senel ${ }^{1 *}$ and Bülent Mızrak ${ }^{2}$ \\ ${ }^{1}$ MD, Department of Pathology, Kayseri Training and Research Hospital, 38110, Kayseri, Turkey \\ ${ }^{2}$ Prof. Dr. Department of Pathology, BAU International University, Batumi, Georgia.
}

\begin{abstract}
Background: This study's goalis todeterminethe incidence of sudden natural death (SND) based onadult forensic autopsies performed inthe TurgutÖzal Medical Center Research Hospital,its age and genderdistribution, and itscauses and to evaluatehistopathologicalresults from the organs.

Methods: Forensic autopsiesfrom the last 1.5 years were examined retrospectively. Cases of sudden natural death over the age of 15 years were included. The ages and genders of the cases were recorded. Hematoxylin-Eosin stained preparations of organs were examined. The histopathological findings of the heart, lung, liver, kidney, and brain were evaluated.

Conclusions: Sudden natural deathwasmore common in older males. The most common cause wasischemic heart disease. Other causes included non-ischemic heart disease, respiratory system disease, central nervous system disease, gastrointestinal system disease, and urogenital system disease.
\end{abstract}

Keywords: Sudden Natural Death, Autopsy, Ischemic Heart Disease, Turkey

\section{Introduction}

In cases of sudden natural death, death occurs suddenly and unexpectedly due to a natural cause ${ }^{[1,2]}$. It can be described as the rapid termination of life as a result of an illness. This type of death is considered unexpected when there is an absence of prior disease symptoms or if the symptoms are unknown to the deceased's friends, relatives, or physician ${ }^{[3]}$. In most cases, the person seems to be healthy and is able to do daily chores. If there is no explanation, a postmortem examination and autopsy are required to identify the cause of death ${ }^{[1]}$.

Studies have shown that ischemic heart diseases are the leading causes of sudden natural deaths. The most common is cardiac ischemia, which develops as a consequence of coronary atherosclerosis ${ }^{[4,5]}$. The rate of SND of cardiac origin is approximately $50 \%$, and the causes are mainly a function of age ${ }^{[6,7]}$. The most common cause of SND is connected to cardiovascular system and in turn followed by respiratory, cerebrovascular and, digestive and urogenital systems ${ }^{[8]}$.

This study's goal was to evaluate the causes of sudden natural death in adults and assess histopathological findings in organs from autopsies.

\section{Material and Methods}

The study evaluated 325 autopsies that were performed over a 1.5 year period at İnönü University's Turgut Özal
Medical Center Research Hospital. Sudden natural death cases over 15 years of age were included; 225 cases were not sudden natural death cases and were not evaluated. For the remaining 100 cases, ages and genders were noted. For histological examinations, tissue samples were taken from five main organs (brain, heart, lung, liver, and kidney) of each corpse. Hematoxylin-Eosin stained preparations were evaluated by a pathologist. The age, gender distribution of the cases and the frequency of the organ findings were shown in the tables as percentages.

The set of 225 cases excluded from the study had the following causes of death: 19 died from vaccination, 7 died from carbon monoxide poisoning, 37 died from a trauma (battery, falling), 32 died from gunshot injury, 5 died from sharp object injury, 11 died from drowning, 10 died while being treated in the hospital, 3 died after injection, 8 died in traffic accidents, 3 died from drug intoxication, 6 died from electric shock, 3 died from scorpion sting or snake bite, 6 died from food poisoning, 9 died in fire. Sixty-six of these cases were under the age of 15 years.

\section{Results}

The age distribution of the cases is between 15 and 90 years of age. Cases of sudden natural death are particularly common in 60-70 year old males $(78 \%)$ (Table 1). In all cases, death occurred within 24 hours of the onset of symptoms. 
Myocardial infarction (MI) (Figure 1) was in the most common cause, accounting for $50 \%$ of deaths. Death due to ischemia mostly occurs due to atherosclerotic coronary artery disease.

Excluding ischemia, cardiac causes of death included myocardial hypertrophy $(25 \%)$, cardiomegaly $(4 \%)$, aortic dissection $(3 \%)$, bridging $(2 \%)$, coronary artery thrombus $(3 \%)$, myocarditis $(1 \%)$, and atrial myxoma (1\%) (Table 2$)$.

Lung histopathologies revealed the following: intraalveolar edema (45\%) (Figure 2), hemorrhage (22\%), emphysema $(15 \%)$, pneumonia $(8 \%)$, bronchiolitis $(5 \%)$, foreign body aspiration (3\%), emboli (1\%), and vasculitis (1\%).

Liver histopathologies showed single cell necrosis (76\%), steatosis (30\%) (Figure 3), chronic hepatitis (23\%) (Figure 4 ), cavernous hemangioma (4\%), cirrhotic changes (4\%), and granulomatous inflammation (1\%).
Brain histopathologies showed ischemic changes (26\%), edema (24\%), and subarachnoid hemorrhage (17\%) (Figure 5). Other findings were intraparenchymal hemorrhage $(3 \%)$ and sclerosis in the basilar artery (1\%). No findings were determined in $53 \%$ of the cases.

Renal findings showed chronic pyelonephritis (24\%) (Figure 6), acute tubular necrosis (7\%), simple cysts $(14 \%)$, urolithiasis $(3 \%)$, renal cell carcinoma $(2 \%)$, and amyloidosis (1\%). No findings were determined in $49 \%$ of the cases (Table 2 ).

\section{Discussion}

There is no universally accepted definition of the term sudden death. This confusion is reflected in debates over whether deaths that occur up to a few hours after symptoms become apparent should be regarded as cases of sudden death ${ }^{[9]}$. Some researchers consider deaths within 24 hours

Table 1: Age and gender distribution of SND cases.

\begin{tabular}{|l|c|c|c|}
\hline Age & $\begin{array}{c}\text { Male } \\
\%\end{array}$ & $\begin{array}{c}\text { Female } \\
\%\end{array}$ & $\begin{array}{c}\text { Total } \\
\%\end{array}$ \\
\hline $15-20$ & 4 & 6 & 10 \\
\hline $21-30$ & 4 & 1 & 5 \\
\hline $31-40$ & 11 & 6 & 17 \\
\hline $41-50$ & 16 & 2 & 18 \\
\hline $51-60$ & 16 & 1 & 19 \\
\hline $61-70$ & 16 & 3 & 12 \\
\hline $71-80$ & 9 & 3 & 2 \\
\hline $81-90$ & 2 & 0 & $\mathbf{1 0 0 \%}$ \\
\hline Total\% & $\mathbf{7 8 \%}$ & $\mathbf{2 2} \%$ & \\
\hline
\end{tabular}

Table 2: Frequencies of histological organ findings in SND.

\begin{tabular}{|l|l|c|}
\hline Organs & Histological findings & $\%$ \\
\hline \multirow{5}{*}{ Cardiac findings } & Atherosclerosis & 61 \\
\cline { 2 - 3 } & Myocardial infarct & 50 \\
\cline { 2 - 3 } & Myocardial hypertrophy & 3 \\
\cline { 2 - 3 } & Coronary thrombosis & 1 \\
\cline { 2 - 3 } & Myocarditis & 4 \\
\cline { 2 - 3 } & Arrhythmogenic right vent. cardiomyopathy & 3 \\
\cline { 2 - 3 } & Aortic dissection & 25 \\
\cline { 2 - 3 } & Bridging of coronary arteries & 1 \\
\cline { 2 - 3 } & Atrial myxoma & 2 \\
\hline
\end{tabular}




\begin{tabular}{|c|c|c|}
\hline Organs & Histological findings & $\%$ \\
\hline \multirow{4}{*}{ Pulmonary findings } & Edema & 45 \\
\hline & Intraalveolar hemorrhage & 22 \\
\hline & Emphysema & 15 \\
\hline & Pnömoni & 8 \\
\hline \multirow{4}{*}{ Pulmonary findings } & Pulmonary hypertension & 2 \\
\hline & Foreign body aspiration & 3 \\
\hline & Bronchiolitis & 5 \\
\hline & Embolus & 1 \\
\hline \multirow{5}{*}{ Cerebral findings } & Edema & 24 \\
\hline & Ischemic neurons & 26 \\
\hline & Subarachnoidal hemorrhage & 17 \\
\hline & Intraparenchymal hemorrhage & 3 \\
\hline & Basilar artery sclerosis & 1 \\
\hline \multirow{5}{*}{ Kidney findings } & Chronic pyelonephritis & 24 \\
\hline & Simple cyst & 14 \\
\hline & $\begin{array}{l}\text { Acute tubular necrosis } \\
\text { Urolithiazis }\end{array}$ & $\begin{array}{l}7 \\
3\end{array}$ \\
\hline & Renal cell carcinoma & 2 \\
\hline & Amyloidosis & 1 \\
\hline \multirow{6}{*}{ Liver findings } & Isolated hepatocyte necrosis & 76 \\
\hline & Steatosis & 30 \\
\hline & Chronic hepatitis & 23 \\
\hline & Cavernous hemangioma & 4 \\
\hline & Cirrhosis & 4 \\
\hline & Granulomatous inflammation & 1 \\
\hline Total & & 100 \\
\hline
\end{tabular}

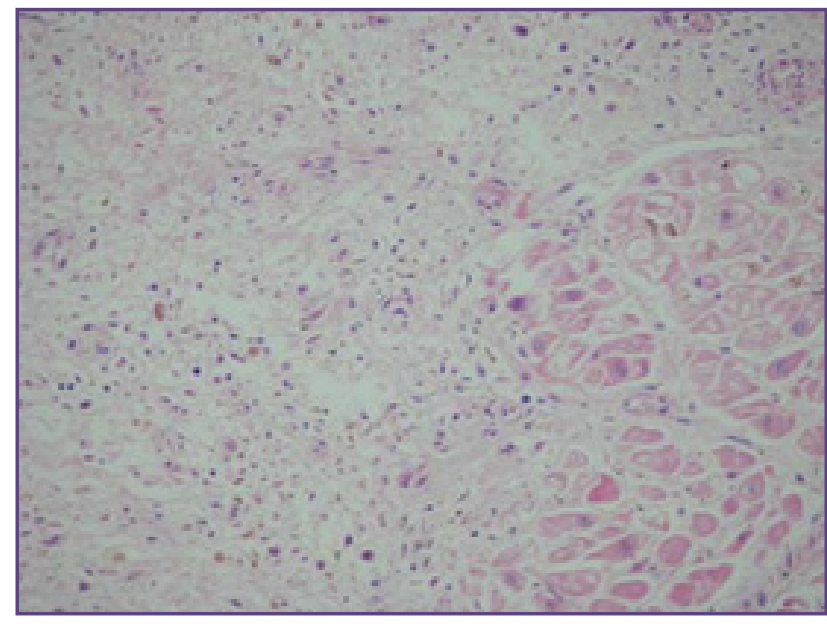

Fig. 1: Myocardial infarctionis characterized by ischemic necrosis findings (H\&E, x200).

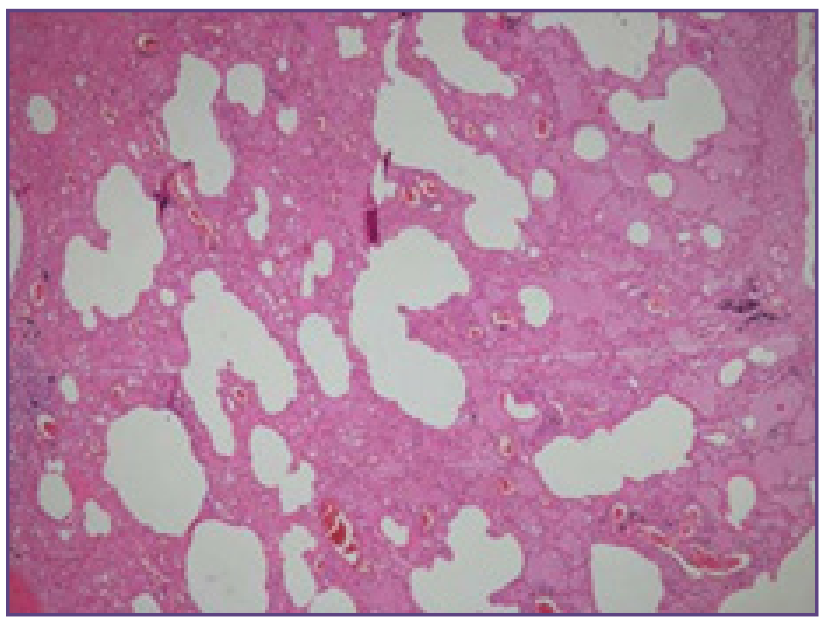

Fig. 2: Intraalveolar edema characterized by fluid accumulation within the alveolar cavities (H\&E, x200). 


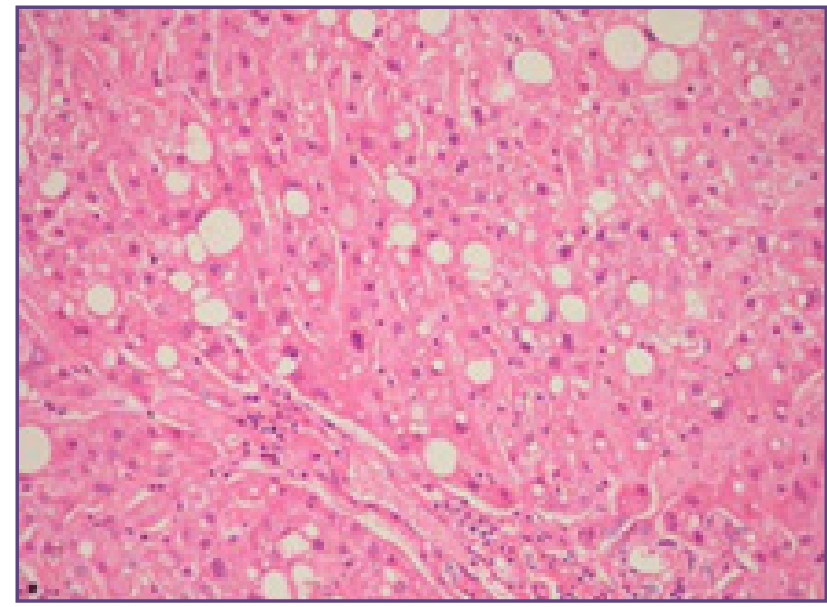

Fig. 3: Steatosis characterized by fat accumulation in the liver parenchyma (H\&E, x200).

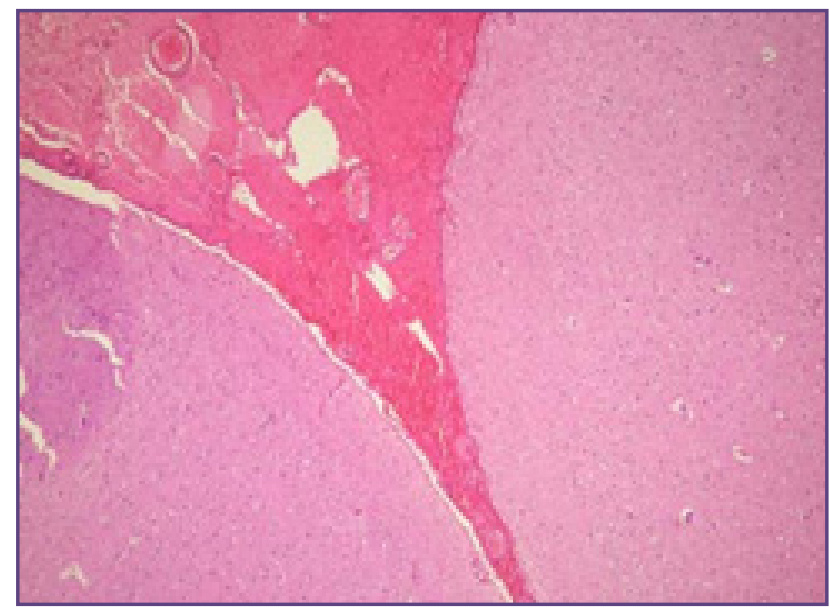

Fig. 5: Subarachnoid hemorrhagecharacterized by bleeding under arachnoid membrane. (H\&E, x200).

of the onset of acute symptoms to be sudden [10,11], but others suggest this term only applies to deaths within 6 hours of the onset of symptoms ${ }^{[12]}$. The maximum period accepted is usually $1-24$ hours ${ }^{[13]}$. In astudy by Dinesh S. Rao et al. ${ }^{[14]}$, the rate of unexplained sudden death cases was reported as $8.67 \%$. In other studies, the rate of sudden and unexpected deaths among natural deaths is reported to be $30 \%{ }^{[15]}$. In the present study, the rate of sudden natural deaths in 259 adults was $38.6 \%$.

More than half of natural deaths are caused by cardiovascular disorders ${ }^{[16]}$. In the literature, the true incidence of sudden cardiac deaths remains unclear, with a wide range in available estimates ${ }^{[17]}$. Among the cardiovascular pathologies, ischemic heart disease is the most common cause for SND ${ }^{[18]}$. Coronary atherosclerosis and acquired forms of cardiomyopathy are the most common findings at

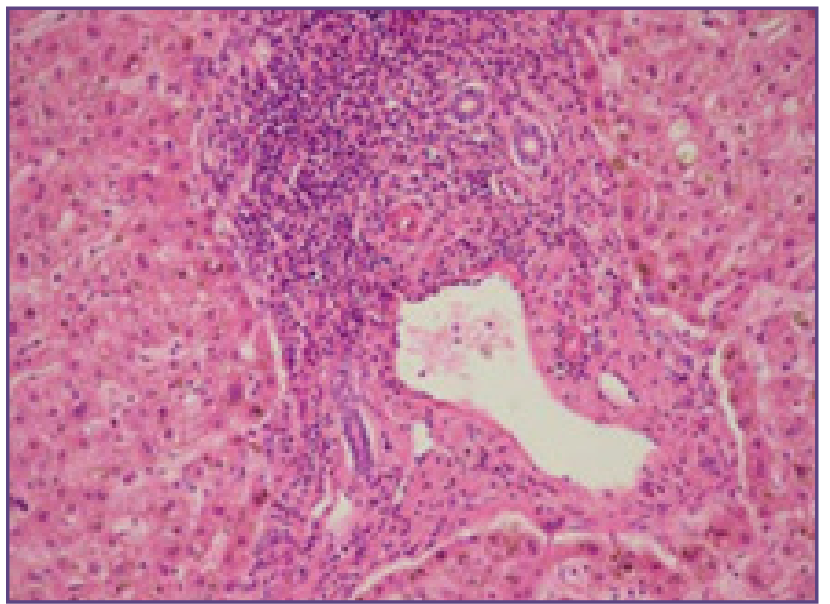

Fig. 4: Chronic hepatitis characterized by chronic inflammatory inflammation of the liver tissue (H\&E, x200).

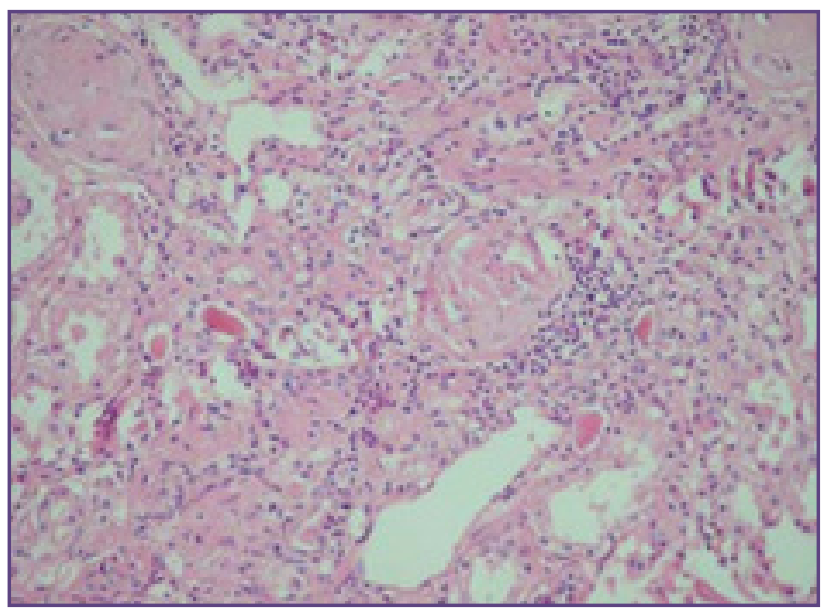

Fig. 6: Chronic pyelonephritis characterized by chronic inflammatory inflammation and glomerulosclerosis of kidney tissue(H\&E, x200).

autopsies of sudden cardiac death in adults ${ }^{[11,19]}$. Coronary atherosclerosis was also seen highly in $61 \%$ of our series. Recent and/or old myocardial infarcts were present in 50\% of cases. Our series had 25\% with myocardial hypertrophy, appearing mainly in hypertension. This can be explained by the higher age group of our cases and high occurrence of hypertension in our population. Epidemiological and autopsy studies suggest a close link between aging and the clinical manifestation of atherosclerosis ${ }^{[20]}$. We found rate of coronary thrombosis as 3\% which was lower than previous studies ${ }^{[1,19]}$. Rate of myocarditis have also extreme variations in the literature $(21)$, and its ratio was $1 \%$ in our population.

Among the cardiovascular disorders, aortic dissection was reported in $1.3 \%$ of cases by Escoffrey and Shirley ${ }^{[21]}$. Puranik et al. ${ }^{[22]}$ also recorded the ratio of cardiac deaths due to aortic dissection as $5 \%$. Aortic dissection were 
found in 3\% of our series. Additionally, we diagnosed atrial myxoma in only one case of our series.

Bruce and Waller ${ }^{[15]}$ determined that 23 of 24 sudden death cases occurred due to ischemic heart disease and that atherosclerotic constriction was detected at the rate of $75 \%$ in at least one main artery in the autopsy. In the present study, atherosclerosis cases had a rate of $61 \%$ and in $41 \%$ of our cases, had atherosclerotic constriction was above $75 \%$. In 20 of our cases, atherosclerotic constriction was below $60 \%$. In this study, $50 \mathrm{MI}$ cases were identified, one had regular coronary arteries, and one also had regular coronary arteries but this was attributed to myocarditis with MI. In a study conducted by Puranik et al. [22], $56.4 \%$ of sudden natural death cases were due to cardiac causes. The most common cardiac cause was arrhythmia (29.0\%). Other cardiac causes were acute myocardial infarction (24.5\%), myocarditis (11.6\%), hypertrophic cardiomyopathy (5.8\%), aortic dissection (5.4\%), and dilated cardiomyopathy (5.4\%). In the present study, aortic dissection was observed at the rate of $3 \%$ and myocarditis was observed at a lower rate, $1 \%$. In this study, bridging had a rate of $2 \%$.

As can be seen in previous studies, heart and lung findings are usually emphasized. In this study, the findings of all organs sent to the pathology laboratory were evaluated. In the majority of previous studies, pulmonary embolism was mentioned among the causes of sudden death.

In our study, most common pulmonary finding was intraalveolar edema as 45\%. It may appear as a complication in various situations such as congestive heart failure, smoke inhalation, tuberculosis, anaphylactic reactions, etc ${ }^{[23]}$. On the other hand, pulmonary histopathologic findings were intraalveolar hemorrhage (22\%), emphysema (15\%), pneumonia $(8.0 \%)$, bronchiolitis $(5 \%)$, and foreign body aspiration (3\%). Pulmonary embolus was seen in $1.0 \%$, vascülitis (1\%). In previously studied series, pulmonary embolus rate was mentioned as 3.4-12.5\% ${ }^{[24,25]}$. But, we found pulmonary embolus rate lower than previous studies. In the study conducted by Puranik et al. ${ }^{[22]}$, death due to asthma was detected (16.1\%). In most cases in the present study, clinical information is not known, but death due to asthma was not detected.

Among the cerebrovascular disorders, subarachnoid hemorrhage and intracerebral hemorrhage are important causes of unexpected death often between the ages of 40 70 years ${ }^{[26]}$. In central nervous system, ischemic red neuron was our most prominent finding with $26 \%$ frequency in our study. The high percentage of this finding may be explained by its occurrence in different death situations such as cardiovascular, cerebrovascular and pulmonary failure. Cerebral edema was seen in $24 \%$ of cases, and former explanation is also valid for this entity. In Puranik et al.'s study ${ }^{[22]}$, intraparenchymal hemorrhage had a rate of $23.8 \%$. In the present study, intraparenchymal hemorrhage had a rate of $3 \%$ and subarachnoid hemorrhage had a rate of $17 \%$.

In liver, isolated hepatocyte necrosis was seen in $76 \%$ of cases. This high percentage is striking among the findings. Isolated hepatocyte necrosis is associated with hepatitis, drug and alcohol abuse, toxications etc ${ }^{[27]}$. Chronic hepatitis was $23 \%$ in liver lesions as a high occurrence in our population, and it can be easily said that hepatitis is also major public health problem for our population. Steatosis was present in 30 cases, but this is not an important histopathologic finding, occurs in obesity, hepatitis, alcoholism etc. and it is reversible. Our liver results were similar with the previous studies ${ }^{[28,29]}$.

As a regard of kidney findings, chronic pyelonephritis was most frequent (24\%) of kidney lesions, and this finding may also be assessed as a threat for public health in this population, because it culminates in renal insufficiency if persists ${ }^{[30]}$. Acute tubular necrosis was found in $7 \%$ of kidney lesions. It is the most common cause of intrinsic acute renal failure and usually occurs after an acute ischemic or toxic event ${ }^{[31]}$. We can say that simple cysts are seen in old ages, and they have no clinical importance. Renal cell carcinoma was detected in both of our cases.

\section{Conclusion}

Ischemic heart diseases remain the number one cause of sudden natural death. Other causes include non-ischemic heart diseases, respiratory system diseases, central nervous system diseases, gastrointestinal system, and genitourinary system diseases. It is important to emphasize that the cause of death may not be identified in some cases. Finally, exact cause of SND cannot be determined by using routine autopsy procedures and needs further investigations. In medicolegal autopsies, especially for SND, we propose that every possible organ must be sampled for histological examination, and must be evaluated with a multidisciplinary approach (scene investigation, medical history, biochemical, microbiological, toxicological, etc.). Thereby, cause of death can be accurately determined in SND cases.

\section{References}

1. Simpson K, Knight B. Forensic Medicine 9th ed, pp. Great Britain: Hodder Arnold; 1985.

2. Spivak J, Verdain B. Manuel of Clinical Problems in İnternal Medicine 3 th ed, pp. 1982; 356-9. 
3. Soysal Z, Eke SM, Çağdır AS. Doğal Nedenlere Bağlı Ani Ölümler. Adli Otopsi. İstanbul Üniversitesi Cerrahpaşa Tıp Fakültesi Yayınları; 1999.

4. Virmani R, Burke AP, Farb A (2001). Sudden cardiac death. Cardiovas Pathol. 2001; 10: 211-18.

5. Luqman M, Sattar A, Abbasi S, Satti TM. Pattern of sudden deaths in armed forces personnel - posmortem study. Pak Armed Forces Med J. 1995; 45: 66-71.

6. Hort W. Arteriosclerosis. Its morphology in the past and today. Basic Res Cardiol. 1994; 89: 1-15.

7. Stary HC, Chandler AB, Glagov S, et al (1994). A definition of initial, fatty streak, and intermediate lesions of atherosclerosis. A report from the Committee on Vascular Lesions of the Council on Arteriosclerosis, American Heart Association. Arterioscler Thromb. 1994; 14: 840-856.

8. Spooner PM, Priori SG, Myerburg RJ. Spotlight on sudden cardiac death. Cardiovasc Res 2001; 50: 173-6.

9. Polat O, Akça S, Günhan Ö, Finci R. Doğal Kökenli Ani Ölümler. Adli Tıp Derg. 1989; 5: 165-9.

10. Tunstall-Pedoe H, Kuulasmaa K. Amouyel P. etal. Myocardial infarction and Coronory deaths in the World Health Organization MONICA Project registration procedures, event rates, and case-fatality rates in 38 populations from 21 countries in four continents. Circulation. 1994; 90: 583-612.

11. Virmani R. Burke AP and Farb A. Sudden cardiac death. Cardiovasc Pathol. 2001; 10: 275-282.

12. Ezra A. Cardiology Clin. 1987; 5: 337-343.

13. DiMaio WJ, DiMaio D. Deaths Due to Natural Disease. Forensic Pathology. 2 nd ed, New York: CRC press; 2001. 43-46.

14. Dinesh S Rao, Yadhukul. Sudden and Unexpected Natural Deaths-A-Four-Year Autopsy Review. JPAFMAT. 2008; 8(2).

15. Bruce F, Waller A. Postgr, Med. 1998; 83: 273-282.

16. Anderson R E, Hill RB, Broudy DW, Key CR and Pathak D. A population based autopsy of Sudden, Unexpected deaths from Natural causes among persons 5 to 39 yrs old during a 12 year period. Human Pathol. 1994; 25: 1332-40.

17. Kong MH, Fonarow GC, Peterson ED, et al. Systematic review of the incidence of sudden cardiac death in the United States. J Am Coll Cardiol. 2011; 57: 794-801.
18. Saukko P, Knight B. Knight's forensic pathology. 3rd ed, London: Arnold; 2004.

19. Virmani R, Burke AP, Farb A. Sudden cardiac death. Cardiovasc Pathol. 2001; 10: 211-8.

20. Orlandi A, Bochaton Piallat ML, Gabbiani G, Spagnoli LG. Aging, smooth muscle cells and vascular pathobiology: implications for atherosclerosis. Atherosclerosis. 2006; 188: 221-30.

21. Escoffery CT, Shirley SE. Causes of sudden natural death in Jamaica: a medicolegal (coroner's) autopsy study from the University Hospital of the West Indies. Forensic Sci Int. 2002; 129: 116-21.

22. Puranik R, Chow CK, Duflou JA, Kilborn MJ, McGuire MA. Sudden death in the young. Depart of Cardiol. 2005; 447: 742-6.

23. Yilmaz R, Yuksekbas O, Erkol Z, Bulut ER, Arslan MN. Postmortem findings after anaphylactic reactions to drugs in Turkey. Am J Forensic Med Pathol. 2009; 30: 346-9.

24. Puranik R, Chow CK, Duflou JA, Kilborn MJ, McGuire MA. Sudden death in the young. Heart Rhythm. 2005; 2: 1277-82.

25. Vanbrabant P, Dhondt E, Sabbe M. What do we know about patients dying in the emergency department? Resuscitation. 2004; 60: 163-70.

26. Amakiri CNT, Akang EEU, Aghadiuno PU, Odesanmi WO. A prospective study of coroner' autopsies in University College Hospital, Ibadan, Nigeria. Med Sci Law. 1997; 37: 69-75.

27. Hoek JB, Pastorino JG (2004). Cellular signaling mechanisms in alcohol-induced liver damage. Semin Liver Dis. 2004; 24: 257-72.

28. DiMaio WJ, DiMaio D. Forensic pathology. 2nd ed. London, New York, Washington: CRC Press; 2001.

29. Simpson K, Knight B. Forensic medicine. 11th ed. London: Hodder Arnold Publication; 1997.

30. Kunin CM. Does kidney infection cause renal failure? Annu Rev Med. 1985; 36: 165-76.

31. Cheung CM, Ponnusamy A, Anderton JG. Management of acute renal failure in the elderly patient: a clinician's guide. Drugs Aging. 2008; 25: 455-76.

*Corresponding author:

Fatma Senel, MD, Department of Pathology, Kayseri Training and Research Hospital, 38110, Kayseri, Turkey

Email: drfatmasene12@gmail.com

Financial or other Competing Interests: None. 